\title{
The Application of Bacillus subtilis for Adhesion Inhibition of Pseudomonas and Preservation of Fresh Fish
}

\author{
Wen Zhang, Qiuxia Tong, Jiahong You, Xucong Lv, Zhibin Liu and Li Ni *(D)
}

check for updates

Citation: Zhang, W.; Tong, Q.; You, J.; Lv, X.; Liu, Z.; Ni, L. The Application of Bacillus subtilis for Adhesion Inhibition of Pseudomonas and Preservation of Fresh Fish. Foods 2021, 10, 3093. https://doi.org/10.3390/ foods10123093

Academic Editor: Barbara Cardazzo

Received: 25 October 2021

Accepted: 8 December 2021

Published: 13 December 2021

Publisher's Note: MDPI stays neutral with regard to jurisdictional claims in published maps and institutional affiliations.

Copyright: (c) 2021 by the authors. Licensee MDPI, Basel, Switzerland. This article is an open access article distributed under the terms and conditions of the Creative Commons Attribution (CC BY) license (https:// creativecommons.org/licenses/by/ $4.0 /)$.
Institute of Food Science and Technology, College of Biological Science and Technology, Fuzhou University, Fuzhou 350108, China; zhangwen@fzu.edu.cn (W.Z.); 17750231184@163.com (Q.T.); youjiahong666@163.com (J.Y.); xucong1154@fzu.edu.cn (X.L.); liuzhibin@fzu.edu.cn (Z.L.)

* Correspondence: nili@fzu.edu.cn; Tel.: +86-591-22866378

\begin{abstract}
Inhibiting the growth of spoilage bacteria, such as Pseudomonas spp., is key to reducing spoilage in fish. The mucus adhesion test in vitro showed that the adhesion ability of Bacillus subtilis was positively correlated with its inhibition ability to Pseudomonas spp. In vivo experiments of tilapia showed that dietary supplementation with B. subtilis could reduce the adhesion and colonization of Pseudomonas spp. in fish intestines and flesh, as well as reduce total volatile basic nitrogen (TVB-N) production. High throughput and metabolomic analysis showed treatment with B. subtilis, especially C6, reduced the growth of Pseudomonas spp., Aeromonas spp., Fusobacterium spp., and Enterobacterium spp., as well as aromatic spoilage compounds associated with these bacteria, such as indole, 2,4-bis(1,1-dimethylethyl)-phenol, 3-methyl-1-butanol, phenol, and 1-octen-3-ol. Our work showed that $B$. subtilis could improve the flavor of fish by changing the intestinal flora of fish, and it shows great promise as a microecological preservative.
\end{abstract}

Keywords: Bacillus subtilis; Pseudomonas; adhesion inhibition; preservation

\section{Introduction}

Fresh fish spoil due to the action of a consortium of microorganisms. Specific spoilage organisms (SSOs) have the ability to produce metabolites that directly affect the sensory properties of the product, resulting in its rejection by consumers [1,2]. The inhibition of SSOs by applying appropriate preservation strategies can retain fish freshness and extend shelf life [3,4]. Many studies have focused on the application of biological preservatives in fish products, such as fish filets or surimi [5,6]. Most biological preservatives are metabolites of plants or microorganisms. They are usually sprayed, soaked in products, or added to surimi [7]. However, in whole fish, the fish tends to spoil from the intestines, so these methods are not applicable [8]. Therefore, new preservation methods are needed to encompass a broader range of fish products $[9,10]$.

The predominant spoilage bacteria of chilled fish mainly include the Pseudomonas, Aeromonas spp., and Shewanella spp. [11,12]. As the microorganisms carried by fish come from the environment, infection is mainly through adhesion to the gastrointestinal tract and the gill mucosa of fish [13]. Cell adhesion is essential for spoilage bacteria's infection of the host. Therefore, stopping bacterial adhesion is crucial to blocking infection [14]. Probiotics have been used to block pathogen adhesion. For example, Lactobacillus spp. with a high adhesive ability was found to inhibit the adhesion of salmonella spp. to epithelial cells by $62.58 \%$ [15]. In an adhesion antagonism experiment, the co-incubation of Escherichia coli infected Caco-2 cells with B. subtilis reduced the adhesion of E. coli strain in the cells [16]. $B$. subtilis can reduce its adhesion, colonization, and overgrowth in human intestines by inhibiting Staphylococcus aureus quorum sensing [17]. B. subtilis is currently the most commonly used probiotic in aquaculture. It can be colonized in the body by adhering to epithelial cells and regulating the composition of animal gastrointestinal flora to prevent pathogenic microorganisms from infecting the host [18,19]. 
Our previous study found that $B$. subtilis could inhibit spoilage bacteria and prolong the shelf life of chilled large yellow croaker (total number of bacteria, TVB-N and K value were used as indexes) [20]. Therefore, in this work, we screened six B. subtilis strains isolated from tilapia for in vitro and in vivo adhesion and spoilage tests. In vitro and in vivo studies were used to measure the adhesion of the B. Subtilis and inhibition on the adhesion of spoilage bacteria, as well as to explore B. subtilis' ability to maintain the balance of gastrointestinal flora and inhibit the production of putrefactive volatile flavor substances in fish. This study may provide theoretical guidance for the development of microecological preservative preparations.

\section{Materials and Methods}

\subsection{Experimental Materials and Strains}

B. subtilis and Pseudomonas spp. (L.) were isolated and identified from tilapia by the Institute of Food Science and Technology of Fuzhou University. In this study, six strains of B. subtilis with different adhesion properties were screened according to adhesion index (self-coacervation rate, hydrophobicity, biofilm, etc., data were not shown) for in vitro and in vivo tests. The sequence accession numbers of the strains used in this study are shown in Table 1. The selected phylogenetic tree of B. subtilis is shown in appendix Figure S1. The fresh tilapia was obtained from the Freshwater Fisheries Research Institute of Fujian.

Table 1. The GenBank accession number of the nucleotide sequence of the experimental strain.

\begin{tabular}{cc}
\hline Strain & GenBank Accession Number \\
\hline Bacillus subtilis B02 & OL423511 \\
\hline Bacillus subtilis B08 & OL423512 \\
\hline Bacillus subtilis B15 & OL423514 \\
\hline Bacillus subtilis B18 & OL423516 \\
\hline Bacillus subtilis C6 & OL423515 \\
\hline Bacillus subtilis C15 & OL423517 \\
\hline Pseudomonas spp. L. & OL423525 \\
\hline
\end{tabular}

\subsection{Determination of the Adhesion Ability of B. subtilis In Vitro}

Larsen's method was employed for collecting tilapia intestinal mucus [21]. To each hole of a 96-well plate, $150 \mu \mathrm{L}$ mucus was added and incubated at $4{ }^{\circ} \mathrm{C}$ overnight (fixed for $18 \mathrm{~h}$ ). The residual mucus was washed twice with $200 \mu \mathrm{L}$ sterile PBS solution. To the wells, $150 \mu \mathrm{L}$ B. subtilis solution labeled with FITC was added and incubated at $30^{\circ} \mathrm{C}$ for $90 \mathrm{~min}$. The wells were washed twice with sterile normal saline to remove the bacteria that did not adhere, and $150 \mu \mathrm{L}$ SDS (1\%) solution was added to each well. The well plate was incubated in an oven at $60{ }^{\circ} \mathrm{C}$ for $1 \mathrm{~h}$. The detection of fluorescence was carried out using a multiscan fluorometer (SpectraMax i3+MiniMax, Molecular Devices, Sunnyvale, CA, USA) with three wells in each group. SDS (1\%) was used as a blank control group. The instrument settings were as follows: excitation wavelength: $495 \mathrm{~nm}$; emission: $525 \mathrm{~nm}$; optical position: bottom; sensitivity: auto; and replicates per sample: 12 . The adhesion rate was calculated using Equation (1).

$$
\text { Adhesion rate }(\%)=\frac{A_{1}-A_{0}}{A_{2}} \times 100 \%
$$

where $A_{1}$ and $A_{2}$ are the fluorescence intensities of $B$. subtilis after adhesion and pure $B$. subtilis suspension, respectively; $A_{0}$ is the fluorescence intensity of the blank group. 


\subsection{Determination of the Adhesion Inhibition Ability of B. subtilis to Pseudomonas spp.}

According to Forestier's method, the simulated fish intestine mucus model was prepared [22]. For competition inhibition, the FITC-labeled Pseudomonas spp. The L. suspension was mixed with $B$. subtilis in equal volumes. To the pore plate coated with mucus, $200 \mu \mathrm{L}$ of the mixture was added and incubated at $30^{\circ} \mathrm{C}$ for $2 \mathrm{~h}$. For displacement inhibition, FITC-labeled Pseudomonas spp. L. suspension was added and incubated for $2 \mathrm{~h}$. Non-adherent bacteria were removed, and then B. subtilis suspension was added, followed by incubation for $2 \mathrm{~h}$. For exclusion inhibition, B. subtilis suspension was added first, and then FITC-labeled Pseudomonas spp. L. was added. After the incubation of three kinds of adhesion inhibition reactions, the cells were flushed twice with sterile PBS. The adhered cells were released and lysed with $150 \mu \mathrm{L}$ of a SDS $(1 \%)$ solution at $60{ }^{\circ} \mathrm{C}$ for $1 \mathrm{~h}$. The fluorescence intensity was measured using the multiscan fluorometer in the same way as in Section 2.2. The adhesion inhibition rate was calculated using Equation (2).

$$
\text { Adhesion inhibition rate }(\%)=1-\frac{A_{2}}{A_{1}} \times 100 \%
$$

where $A_{2}$ and $A_{1}$ are the fluorescence intensity of Pseudomonas spp. L. adhering to the fish intestinal mucus in the presence and absence of $B$. subtilis, respectively.

\subsection{In Vivo Adhesion Test}

\subsubsection{Feeding Experiment of Tilapia}

The suspension of B. subtilis was sprayed on the surface of the basal fish feed, forming a probiotic supplemented fish feed with B. subtilis. The content of B. subtilis in the feed was $1 \times 10^{8} \mathrm{CFU} / \mathrm{g}$. About 160 juvenile tilapias were randomly divided into four groups. Five milliliters of $1 \times 10^{8} \mathrm{CFU} / \mathrm{mL}$ of Pseudomonas spp. L. suspension was added to water. The control group (L group) was fed with basic feed, and the experimental groups (C6 + L group, C15 + L group, B18 + L group) were fed with the B. subtilis-supplemented feed. The fish in the same group were kept in two separated plastic tanks (20 fish per tank, capacity: $50 \mathrm{~L}$ ). Feed was supplied at ten o'clock every day. The cultivation water with a temperature of $23^{\circ} \mathrm{C}$ to $25^{\circ} \mathrm{C}$. During the experiment, approximately $50 \%$ of cultivation water was changed daily, along with the purge of the unconsumed feed and fish feces. After one week of adaptation with basal feed, the feeding experiment lasted one week. The feed used in the feeding experiment was the basic feed provided by Freshwater Fisheries Research Institute of Fujian, and the main ingredients include soybean cake, bran, fishmeal, vitamins, inorganic salts, and fish oil.

\subsubsection{Sample Collection and Processing}

After the feeding experiment, the fish were starved for $24 \mathrm{~h}$. All fish were caught, half of them were slaughtered, and the other half were stored at $4{ }^{\circ} \mathrm{C}$ immediately, because it was found from the preliminary experiment results that the end point of freshness of fish stored at $4{ }^{\circ} \mathrm{C}$ was on the eighth day (TVB-N $>30 \mathrm{mg} / 100 \mathrm{~g}$ ). Thus, at storage for eight days, the other half of the fish were also slaughtered. Five tilapias were randomly selected from each group, and their intestines and flesh were taken. Sterile water was used to wash the intestines and remove fat. About $0.200 \mathrm{~g}$ fish intestines and $0.500 \mathrm{~g}$ dorsal fish flesh were placed in $2 \mathrm{~mL}$ sterile centrifuge tubes, respectively, to extract DNA. The remaining fish were sliced, homogenized, and stored in sterile bags at $4{ }^{\circ} \mathrm{C}$ for the TVB-N test.

\subsection{Determination of Total Volatile Basic Nitrogen (TVB-N)}

For the determination of TVB-N, the method (GB 5009.228-2016, Beijing, China) was used [23]. The homogenized fish sample was weighed to $10.00 \mathrm{~g}$ and transferred to a distillation tube. To the tube, $75 \mathrm{~mL}$ distilled water was added. The mixture was shaken well and soaked for $30 \mathrm{~min}$. The distillation process was carried out in a digiprep total kjeldahl nitrogen systems (K9840, Hanon Technologies Inc., Jinan, China), the $1.00 \mathrm{~g}$ $\mathrm{MgO}$ and $30 \mathrm{~mL}$ boric acid were added, and reacted for $3 \mathrm{~min}$. After distillation, titrate 
receiving solution with $0.0100 \mathrm{~mol} / \mathrm{L}$ hydrochloric acid standard solution was added, and the end color of the mixed indicator solution was purple red. Record the volume value of hydrochloric acid consumed. TVB-N content was calculated using Equation (3).

$$
T V B-N \text { content }\left(\frac{m g}{100 g}\right)=\left(V_{1}-V_{2}\right) \times c \times \frac{14}{m} \times 100
$$

where $V_{1}$ and $V_{2}$ are the volume of hydrochloric acid consumed by the experimental group and reagent blank, respectively $(\mathrm{mL}) ; c$ is the concentration of hydrochloric acid standard solution $(\mathrm{mol} / \mathrm{L})$; and $m$ is the mass of the sample $(\mathrm{g})$.

\subsection{Determination of Volatile Flavor Compounds by GC-MS}

The method published by Wang XF was used to determine volatile flavor compounds, with appropriate modifications [24]. Into a $15 \mathrm{~mL}$ extraction bottle, $2.00 \mathrm{~g}$ flesh were weighed. Five milliliters of saturated $\mathrm{NaCl}$ solution were added, and the mixture was stirred by magnetic stir bar. To the extraction bottle, $200 \mu \mathrm{L}$ of the original concentration of $2 \mathrm{mg} / \mathrm{L}$ standard substance 2,4,6-trimethylpyridine was added. The bottle was capped, the extraction needle was inserted into it, and it was incubated in a $60{ }^{\circ} \mathrm{C}$ water bath for $5 \mathrm{~min}$. The fiber head of the extraction needle was inserted into the bottle for headspace adsorption and extracted for $30 \mathrm{~min}$. After the extraction, the extraction needle was inserted into the GC-MS (7890-B/5977A, Agilent Technologies Inc., Palo Alto, CA, USA) injection port, and it was removed after desorption for $3 \mathrm{~min}$. The GC-MS program consisted of $40^{\circ} \mathrm{C}(3 \mathrm{~min})$, the temperature was raised to $120^{\circ} \mathrm{C}(3 \mathrm{~min})$ at $5{ }^{\circ} \mathrm{C} / \mathrm{min}$, and then raised to $230^{\circ} \mathrm{C}(5 \mathrm{~min})$ at $20^{\circ} \mathrm{C} / \mathrm{min}$. The concentration of compounds was calculated according to the proportion of the peak area of flavor compounds (Equation (4)).

$$
\text { Concentration of volatile components }(\mathrm{mg} / \mathrm{L})=\left(A_{i} / A\right) \times C
$$

where $A_{i}$ and $A$ are the peak areas of volatile component $i$ and the internal standard, respectively, and $C$ is the internal standard concentration $(\mathrm{mg} / \mathrm{L})$.

\subsection{Analysis of Changes of Intestinal Microflora in Tilapia by High-Throughput Sequencing}

The DNA of fish intestine was extracted using a fecal genomic DNA Extraction Kit (Tiangen, Beijing, China). Bacterial primers 341-F (50-CCT AYG GGR BGC ASC AG-30) and 806-R (50-GGA CTA CNN GGG TAT CTA AT-30) were used to amplify the V3-V4 region of bacterial $16 S$ rRNA genes. The sequencing library of bacterial $16 \mathrm{~S}$ rRNA genes was generated for high-throughput sequencing, employing the TruSeqfi DNA PCR-Free Sample Preparation Kit (Illumina, San Diego, CA, USA). Next, the library was sequenced on an Illumina HiSeq2500 platform manufactured by Novogene Bioinformatics Technology Co., Ltd. (Beijing, China). The NCBI sequence read archive was used for data analysis.

\subsection{Detection of Specific Microflora in Intestine and Flesh of Tilapia by Real-Time Quantitative PCR (qPCR)}

The total DNA of intestinal and flesh microorganisms was extracted using a fecal genomic DNA Extraction Kit and a bacterial genomic DNA extraction kit (Tiangen, Beijing, China), respectively. The total DNA of intestine and flesh was detected using the SYBR Green dye method. The specific primer sequence is shown in Table 2, and it was synthesized by Shanghai Shenggong Co., Ltd. (Shanghai, China). The specific primers were verified, and the logarithm standard curve of the bacterial concentration was drawn. The PCR sequence was as follows: initial denaturation $95^{\circ} \mathrm{C} 30 \mathrm{~s}$; denaturation $95^{\circ} \mathrm{C} 5 \mathrm{~s}$; anneal $60{ }^{\circ} \mathrm{C} 30 \mathrm{~s}$; extend $72{ }^{\circ} \mathrm{C} 30 \mathrm{~s}$. A total of 42 cycles were performed. The dissolution curve analysis program was as follows: $95^{\circ} \mathrm{C}$ for $15 \mathrm{~s} ; 60^{\circ} \mathrm{C}$ for $30 \mathrm{~s} ; 3^{\circ} \mathrm{C} / \mathrm{min}$ to $95^{\circ} \mathrm{C}$ for $15 \mathrm{~s}$. 
Table 2. Specific primer sequence of the strain.

\begin{tabular}{ccc}
\hline Strain & Primer & Sequence $\left(\mathbf{5}^{\prime} \rightarrow \mathbf{3}^{\prime}\right)$ \\
\hline \multirow{2}{*}{ Total bacteria } & $27-\mathrm{F}$ & AGAGTTTGATCCTGGCTCAG \\
\cline { 2 - 3 } & $1429-\mathrm{R}$ & GGTTACCTTGTTACGACTT \\
\hline \multirow{2}{*}{ Pseudomonas } & Pse-F & CTGCATCATGGCCGGTGACAACATTT \\
\cline { 2 - 3 } & Pse-R & GTCGCATGGCTGTCGGTCTTCAGATC \\
\hline \multirow{2}{*}{ Bacillus subtilis } & Bac-F & AAAGTCTGACGGAGCAACGC \\
\cline { 2 - 3 } & Bac-R & ACCGCCCTATTCGAACGGTA \\
\hline
\end{tabular}

\subsection{Statistical Analysis}

The results of data processing are expressed as mean \pm standard deviation. The data were plotted by GraphPad Prism 8.0 and analyzed by SPSS 22.0's Duncan test.

\section{Results}

\subsection{Adhesion Ability of B. subtilis In Vitro and Adhesion Inhibition to Pseudomonas spp.}

As shown in Figure 1, the in vitro adhesion rate of the six strains of B. subtilis was in the range of $1-10 \%$. The adhesion ability of B. subtilis C6 and B08 was the highest, followed by C15, B15 and B18, and B02. Therefore, B. subtilis with high (C6, B08), medium (C15, B15), and low (B02, B18) adhesion properties were selected for subsequent inhibition on the adhesion of Pseudomonas spp. and in vivo test.

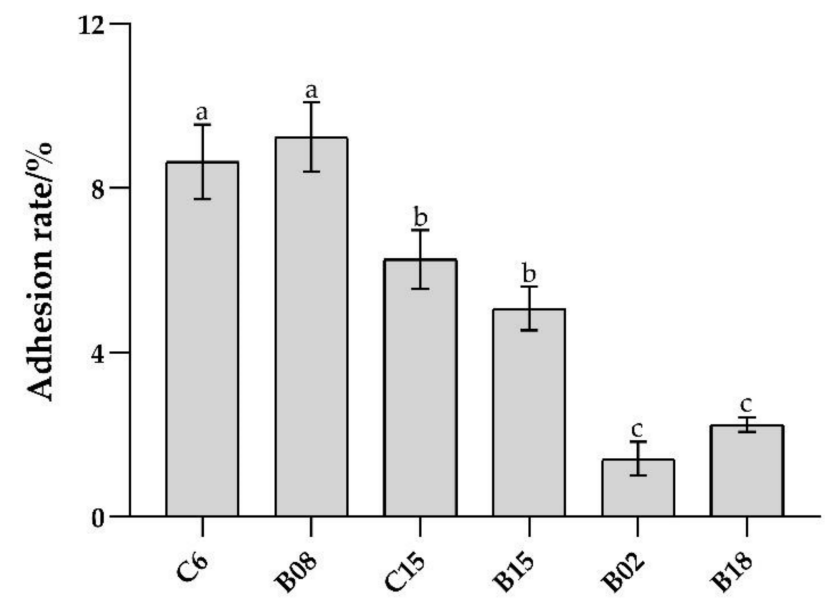

Figure 1. Adhesion ability of six strains of B. subtilis in vitro. Different lowercase letters indicate significant differences at 0.05 level $(p<0.05)$.

Probiotics antagonize spoilage bacteria adhesion mainly through competition, displacement, and exclusion [25]. The adhesion antagonism experiment was carried out by a mucus model in vitro. In the adhesion antagonistic test, high adhesion B. subtilis C6 and B08 had the strongest inhibitory effect on Pseudomonas spp. adhesion $(p<0.05)$, while low adhesion B. subtilis B02 and B18 had weak inhibitory effects (Figure 2). The results indicate that the adhesion ability of B. subtilis is positively correlated with its adhesion antagonism to spoilage bacteria. 


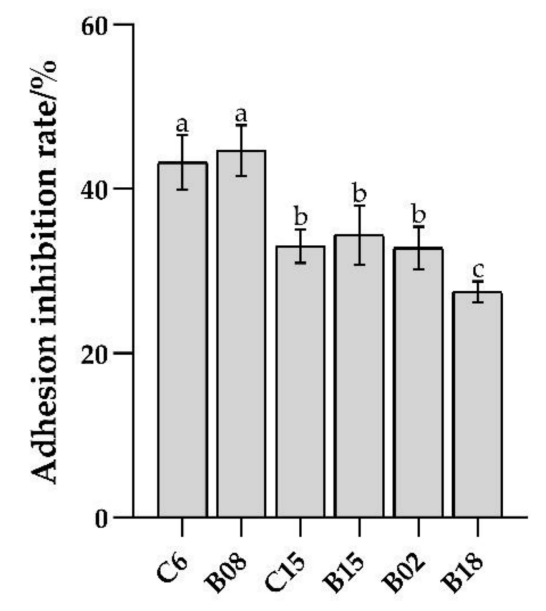

(a)

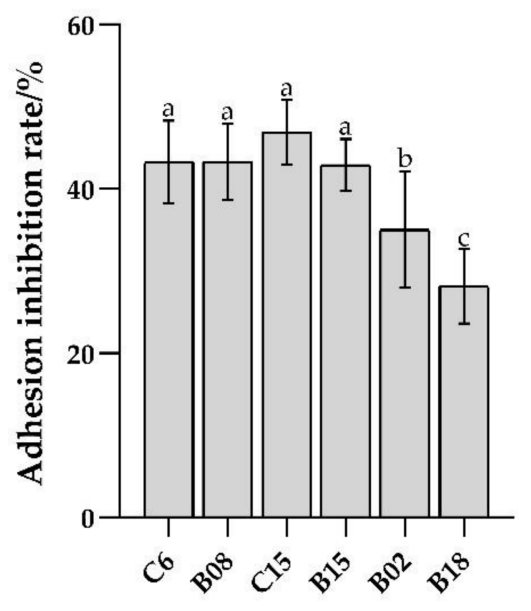

(b)

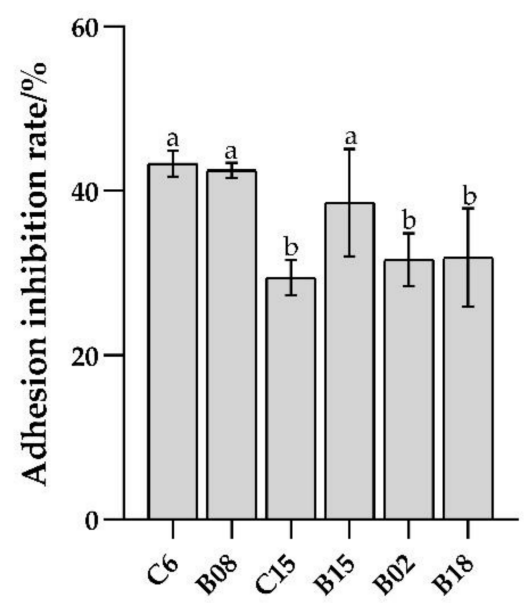

(c)

Figure 2. Adhesion inhibition of six strains of B. subtilis to Pseudomonas spp. L. (a) Competition inhibition; (b) Displacement inhibition; (c) Exclusion inhibition. Different lowercase letters indicate significant differences at 0.05 level $(p<0.05)$.

\subsection{In Vivo Adhesion of B. subtilis and the Preservation Effect on Tilapia}

3.2.1. Effects of B. subtilis on Intestinal Flora Diversity of Tilapia

B. subtilis C6, C15, and B18 with high, medium, and low adhesion and inhibition ability, respectively, were added to the tilapia diet for an in vivo adhesion test. The structure of intestinal flora in high-throughput sequencing results of different treatment groups was analyzed by principal component analysis (PCA).

The spoilage bacteria in fresh fish mainly come from microorganisms in the water environment, most of which are aerobic bacteria [26]. As shown in Figure 3, the bacteria in tilapia intestines during storage for zero days mainly include Fusobacteriaceae, Vibrionaceae, Flavobacteriaceae, Peptostreptococcaceae, Bacteroidaceae, and Pseudomonadaceae. Pseudomonas spp., Flavobacterium spp., Bacteroides spp., Vibrio spp., Fusobacterium spp., and Streptococcus spp. are common spoilage bacteria, which easily attach to the skin, gills, and intestines of fish [27]. Conversely, the diversity of intestinal flora in the supplement B. subtilis C6 feed group was significantly different from that of other treatment groups (Figure 3). The relative abundance of Moraxellaceae and Bradyrhizobiaceae increased, which could provide a hypoxic environment and inhibit the growth of spoilage bacteria [28].

After eight days of cold storage, the dominant bacteria mainly included Enterobacteriaceae, Aeromonadaceae and Streptococcaceae (Figure 3), which are the dominant spoilage bacteria in freshwater fish [29]. As shown in Figure 4, compared with the control group, the relative abundance of Moraxellaceae and Clostridiaceae in the supplemented feed group increased at zero days of storage, while the relative abundance of Fusobacteria spp. and Aeromonas spp. decreased. Similarly, the relative abundance of Fusobacteria spp. and Aeromonas spp. in the supplemented feed group decreased after eight days of storage (Figure 4). 


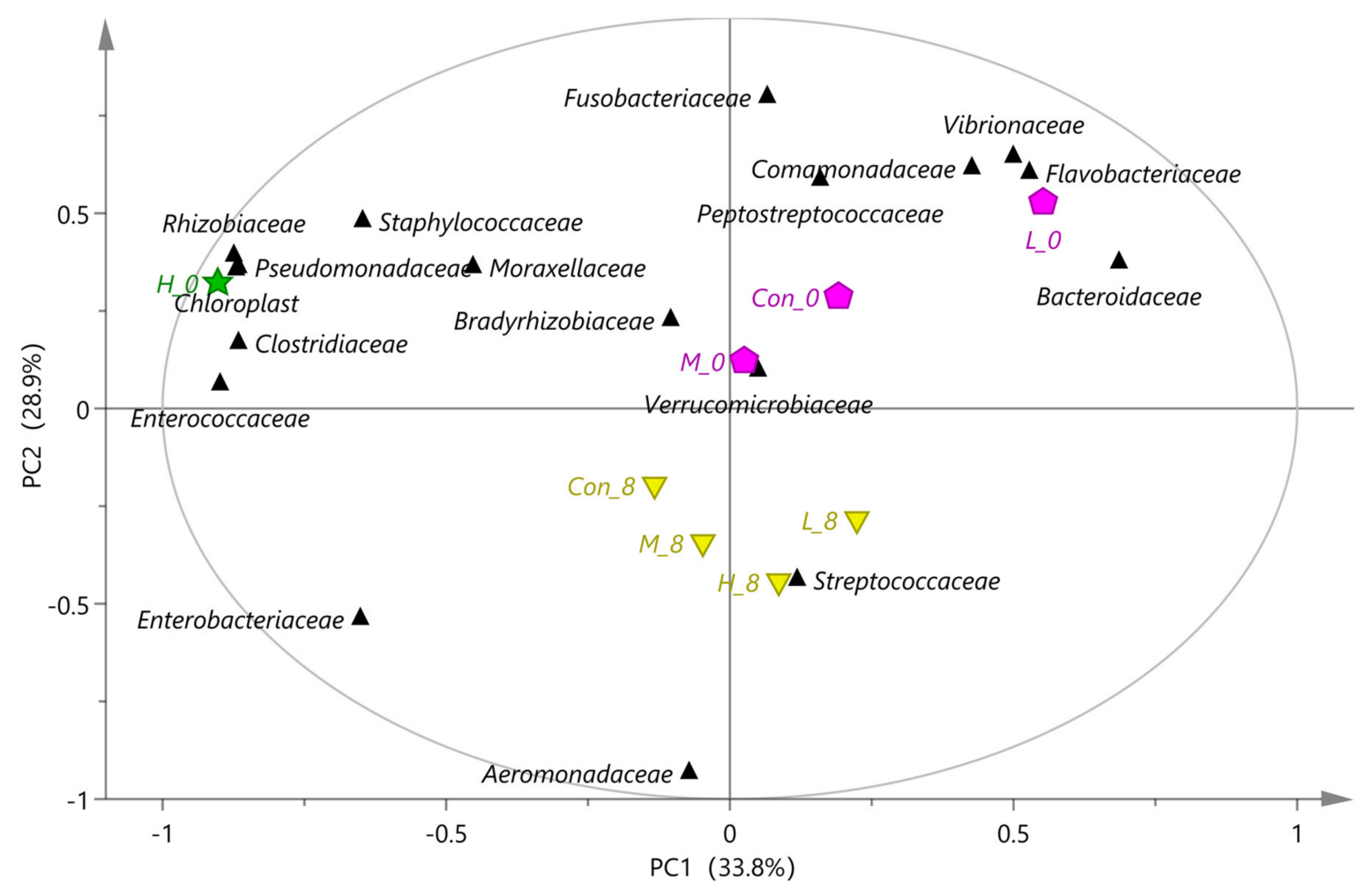

Figure 3. The PCA biplot plot of high throughput sequencing results of intestinal flora. The control group (Con_0: Refrigerate for zero days; Con_8: Refrigerate for eight days) was fed with common feed, and the experimental groups (C6 + L (H_0, H_8), C15 + L (M_0, M_8), B18 + L (L_0, L_8)) were fed with the supplemented B. subtilis feed. Different colors represent different clustering groups.
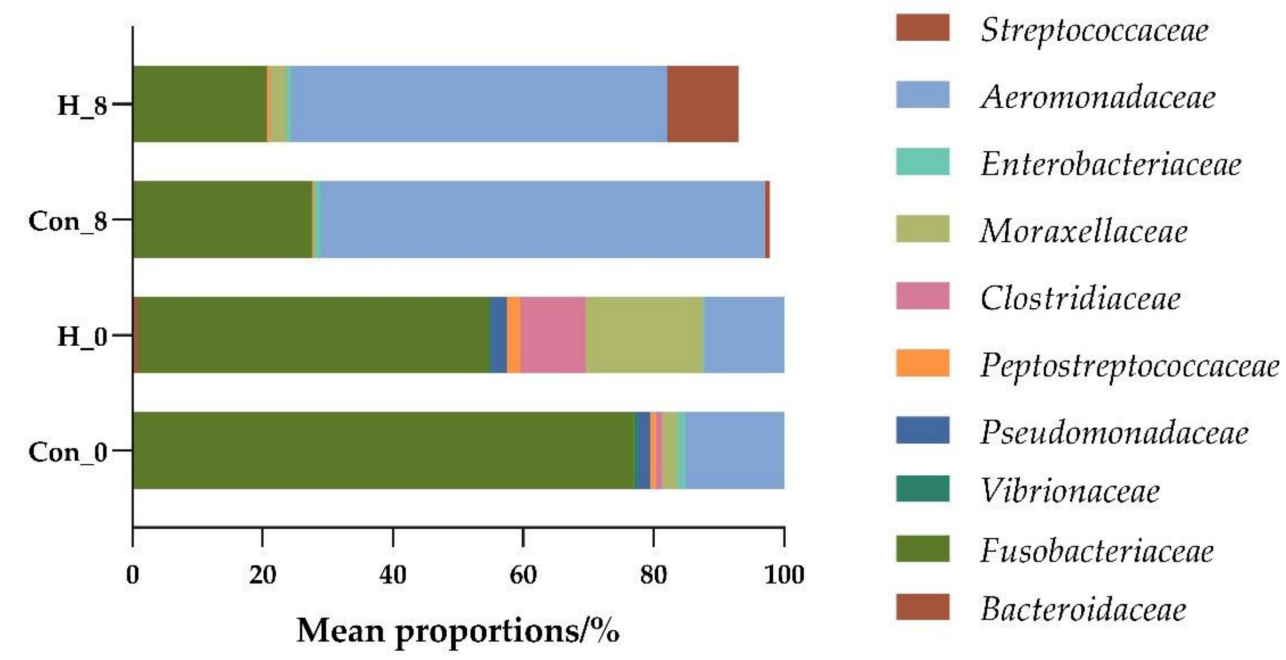

Figure 4. Difference analysis of the mean proportion of the top 10 flora in the high-throughput sequencing results of tilapia intestinal flora in the control group (Con_0: Refrigerate for zero days; Con_8: Refrigerate for eight days) and high adhesion B. subtilis C6 experimental group (H_0, H_8).

Therefore, B. subtilis plays an important role in inhibiting the initial adhesion, growth, and reproduction of spoilage bacteria, as well as in maintaining the balance of intestinal flora in fish [30].

\subsubsection{Analysis of Target Flora in Fish Intestines and Flesh by qPCR}

The adhesion and colonization of $B$. subtilis and Pseudomonas spp. in fish intestines and flesh (stored at $4{ }^{\circ} \mathrm{C}$ for zero and eight days) were analyzed by qPCR. As shown in 
Figure 5, the growth of high-adhesion B. subtilis C6 in fish intestine and flesh was the highest (Figure $5 \mathrm{a}, \mathrm{b}, p<0.05$ ). However, the growth of Pseudomonas spp. in fish intestines and proliferation to the flesh were significantly inhibited by B. subtilis C6 (Figure 5c,d, $p<0.05$ ), and the total number of bacteria was the lowest (Figure $5 \mathrm{e}, \mathrm{f})$.

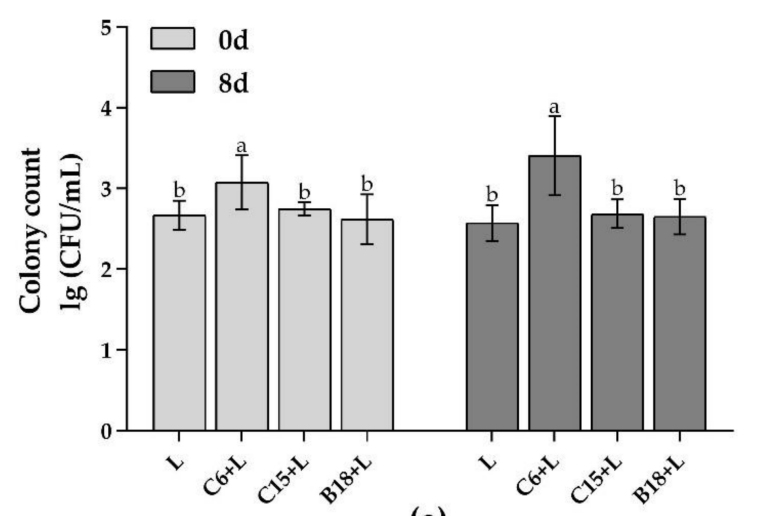

(a)

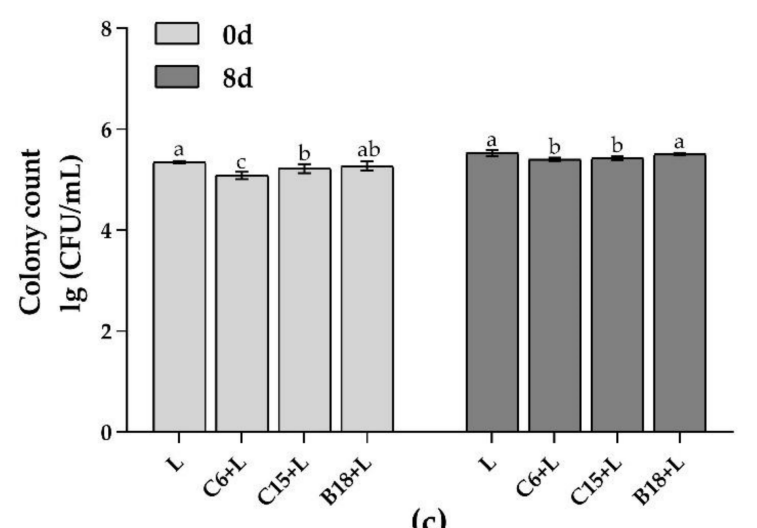

(c)

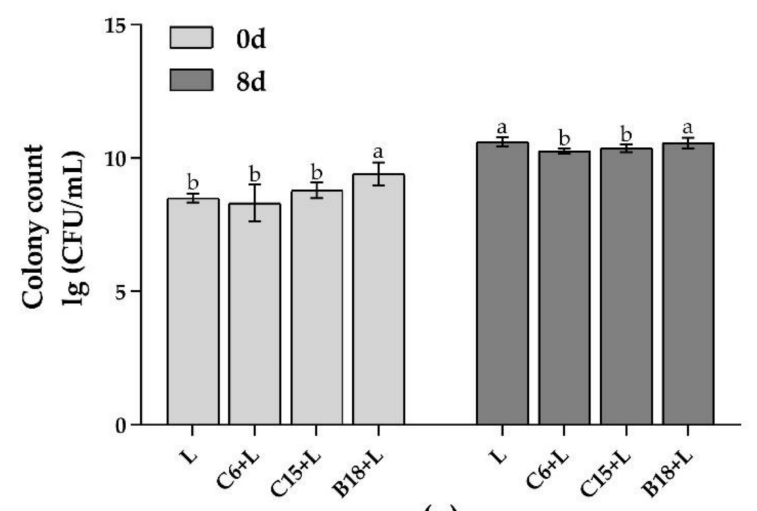

(e)

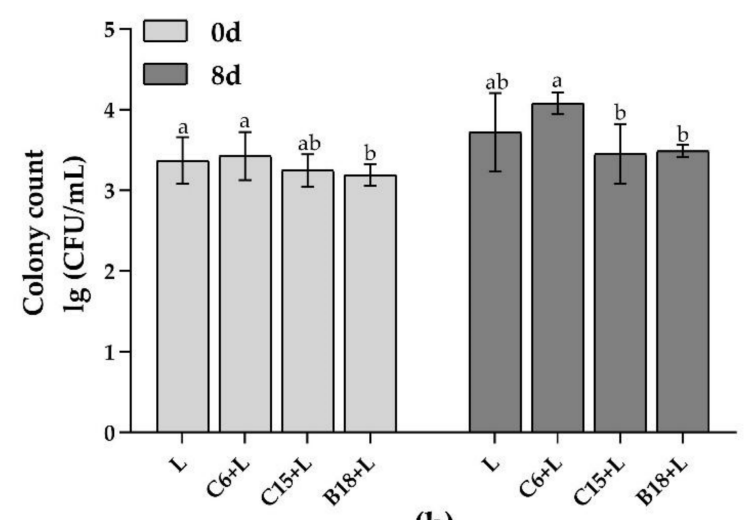

(b)

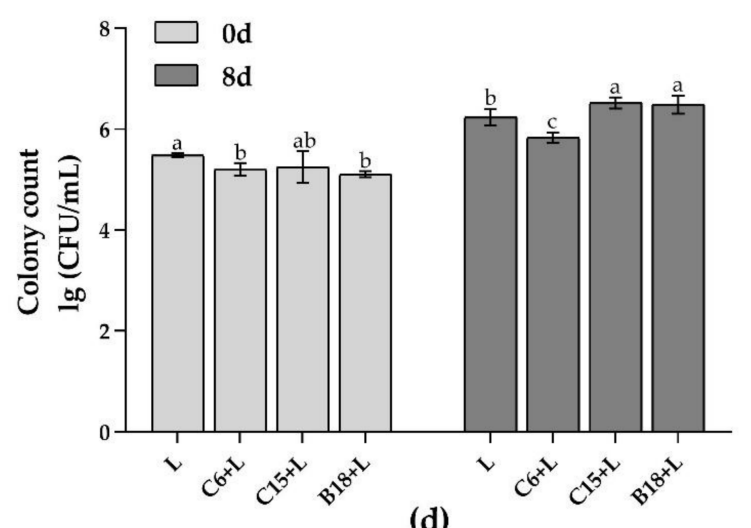

(d)

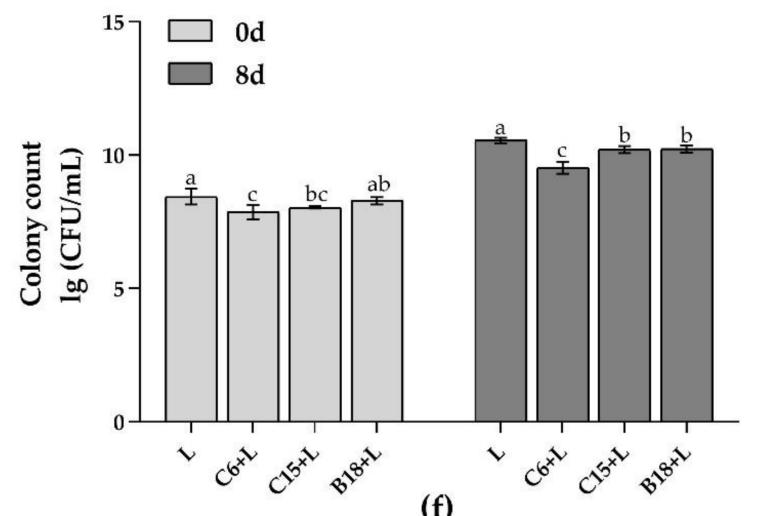

(f)

Figure 5. $\mathrm{qPCR}$ analysis of $\mathrm{f}$ bacterial growth in the intestine $(\mathbf{a}, \mathbf{c}, \mathbf{e})$ and flesh $(\mathbf{b}, \mathbf{d}, \mathbf{f})$ of tilapia during storage at $4{ }^{\circ} \mathrm{C}$. $(\mathbf{a}, \mathbf{b})$ B. subtilis. (c,d) Pseudomonas. (e,f) Total number of bacteria. Different lowercase letters indicate significant differences at 0.05 level $(p<0.05)$. 
The results show that the B. subtilis $\mathrm{C} 6$ with high adhesion ability had obvious advantages in fish intestines and flesh, and the growth and proliferation of Pseudomonas spp. were inhibited.

\subsection{Analysis of Volatile Flavor Compounds in Fish Flesh}

Seventy-six kinds of flavor compounds were detected by GC-MS in different treatment groups after storage for zero and eight days (Table S1). Based on PLS-DA model analysis, there were 35 kinds of volatile flavor compounds (variable important in projection (VIP) $>1$ ) in each group (as shown in Table S2). The results of principal component analysis (PCA) and difference analysis (control group and high adhesion B. subtilis C6 experimental group) are shown in Figures 6 and 7 . The samples refrigerated at $4{ }^{\circ} \mathrm{C}$ for zero days were located on the positive axis of PC1 (Figure 6), and the high-adhesion B. subtilis treatment group (H_0) were significantly different from the others. The differential substances in the H_0 group mainly included 1,3-bis(1,1-dimethylethyl)-benzene, methoxy-phenyl-oxime, 6-octadecenoic acid, and 1,3-trans,5-cis-octariene, while the Con_0 group included ethanol, alkanes, hexadecanoic acid, ethyl ester, hexadecanal, tetradecanoic acid, and ethyl ester (Figure 7a). Saturated hydrocarbons, such as tetradecane and heptadecane, have mild odors [31]; ethanol has a slight pungent taste [32]; hexadecanoic acid, ethyl ester, and hexadecanal are the main sources of fresh flavor in aquatic animals; tetradecanoic acid and ethyl ester have a slight sweet and waxy smell; and methoxy-phenyl-oxime has a fishy smell $[5,33]$. These are the common flavor compounds of fresh aquatic fish.

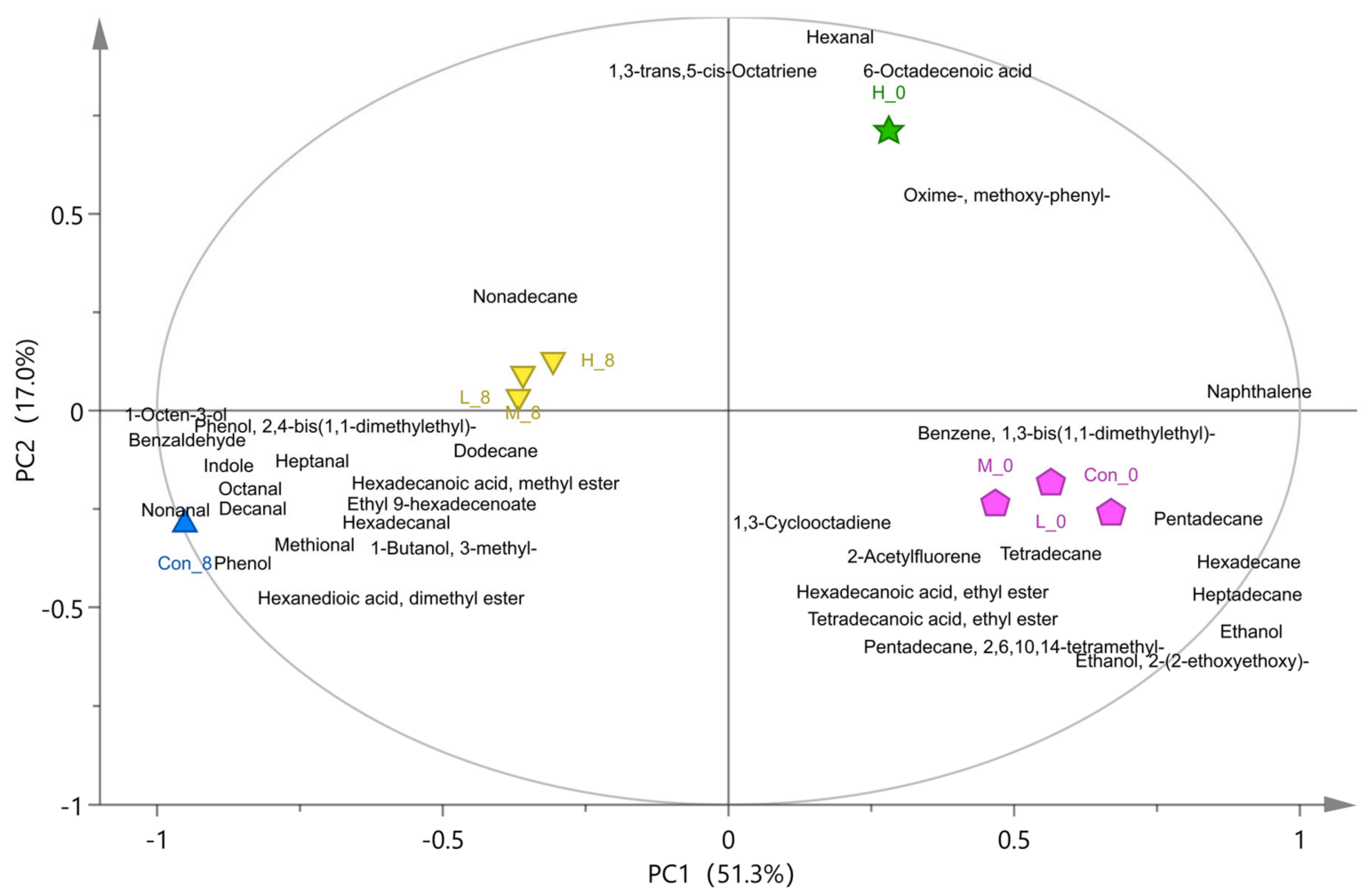

Figure 6. The PCA biplot of volatile compounds in different treatment groups. The control group (Con_0: Refrigerate for zero days; Con_8: Refrigerate for eight days) was fed with common feed, and the experimental groups (C6 + L (H_0, H_8), C15 + L (M_0, M_8), B18 + L (L_0, L_8)) were fed with the supplemented B. subtilis feed. Different colors represent different clustering groups. 


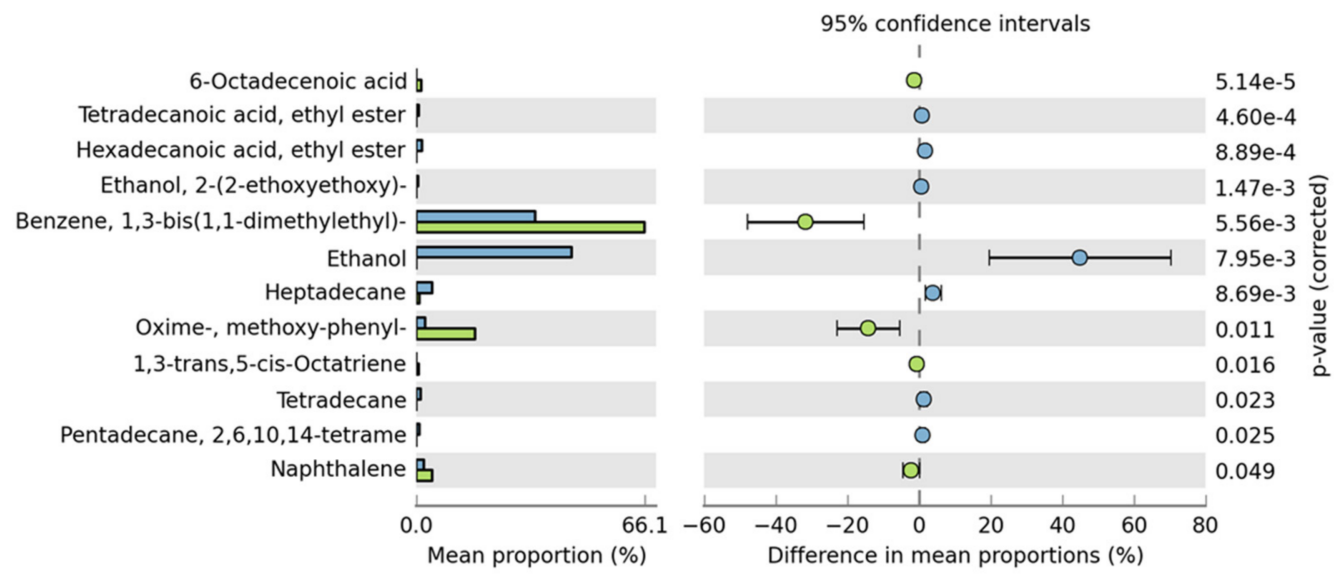

(a)

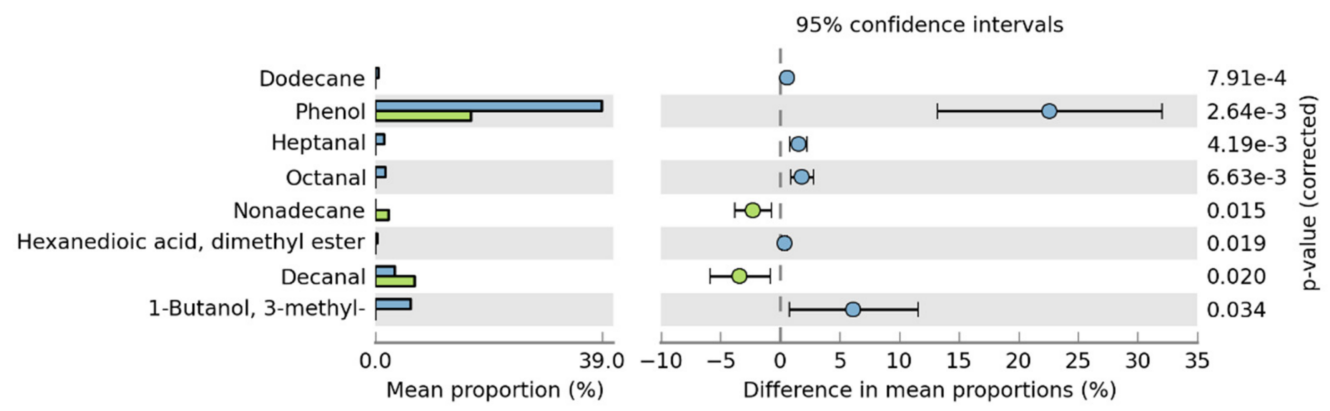

(b)

Figure 7. Difference analysis of control group (Con, blue) and high-adhesion B. subtilis C6 experimental group (H, green); (a) Refrigerated for zero days; (b) Refrigerated for eight days. $(p<0.05)$.

Samples refrigerated for eight days were located on the negative axis of PC1 (Figure 6), and the B. subtilis treatment group was significantly different from the control group. Phenol, 3-methyl-1-butanol, hexanedioic acid, dimethyl ester, octanal, heptanal, indole, 1,3-bis(1,1-dimethylethyl)-benzene, hexadecanoic acid, methyl ester, 2,4-bis(1,1-dimethylethyl)-phenol, 1-octen-3-ol, nonanal, and decanal were the characteristic flavor substances in the control group after eight days of storage (Figures 6 and $7 \mathrm{~b}$ ). Indole has a strong fecal odor [34]; phenol and 2,4-bis(1,1-dimethylethyl)-phenol have the plastic rubber odor, and are the main source of putrid fish odor [35]. C4-C6 alcohols, such as 3-methyl-1-butanol, have a similar anesthetic odor [36]. Hexadecanoic acid and methyl ester have an oily waxy odor, which is also an important component of rancidity. Nonanal, octanal, heptanal, decanal, and other straight chain aldehydes have a citrus peel flavor, fresh green herb flavor, raw potato flavor, and oily nut flavor, respectively. However, when their concentration exceeds a certain threshold, they produce undesirable odors [34]. The production of 1-octen-3-ol is mainly due to fish spoilage [37].

In conclusion, the spoilage bacteria will produce phenol, ethanol, 3-methyl-1-butanol, 2,4-bis(1,1-dimethylethyl)-phenol, indole, and other spoilage flavor compounds. B. subtilis treatment can effectively reduce the production of these spoilage flavor compounds and maintain the flavor of fish. Moreover, the effect of high-adhesion B. subtilis C6 was the most significant.

\subsection{Analysis of TVB-N Content in Fish Flesh}

TVB-N can reflect the degradation of protein in aquatic products, as well as the production of non-protein nitrogen compounds and volatile nitrogen during microbial metabolism, which is one of the key factors used to evaluate the spoilage of aquatic products [38]. In this study, TVB-N content was used as the spoilage index of tilapia, and the changes in TVB-N content in tilapia flesh during storage for zero and eight days were 
determined. As shown in Figure 8, there was no significant difference in TVB-N content between different treatment groups after storage for day zero $(p>0.05)$. After storage for eight days, the three $B$. subtilis strains significantly inhibited the decay process, and the TVB-N content of high-adhesion $\mathrm{C} 6+\mathrm{L}$ and $\mathrm{C} 15+\mathrm{L}$ groups was still within the freshness range (TVB-N $<30 \mathrm{mg} / 100 \mathrm{~g}$ ).

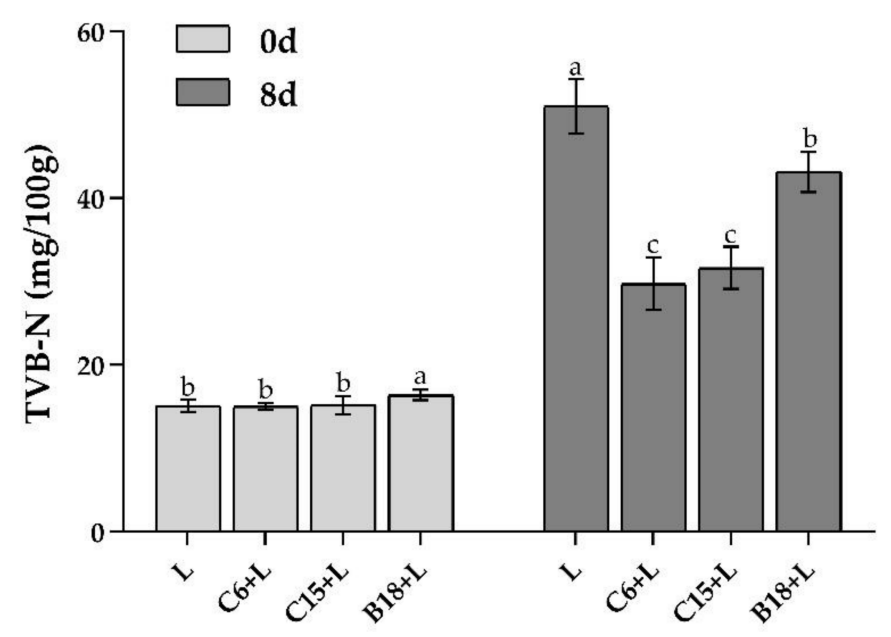

Figure 8. Changes in TVB-N content in fish flesh during storage. Different lowercase letters indicate significant differences at 0.05 level $(p<0.05)$.

\subsection{Correlation Analysis between Intestinal Flora and Volatile Flavor Compounds}

Based on Pearson correlation analysis, the correlation between the dominant flora and the different volatile flavor compounds was analyzed. As shown in Figure 9, in the correlation network analysis diagram, the dominant flora was related to the different volatile flavor compounds. Indole, 1,3-bis(1,1-dimethylethyl)-benzene, 1-octen-3-ol and 2,4-bis(1,1dimethylethyl)-phenol were positively correlated with Aeromonadaceae, Fusobacteriaceae and Enterobacteriaceae. However, the compounds contributing fresh and fishy flavors, such as ethanol, tetradecane, pentadecane, 2,6,10,14-tetramethyl-pentadecane, hexadecanoic acid, ethyl ester, and 1,3-bis(1,1-dimethylethyl)-benzene, were negatively correlated with Enterobacteriaceae and Aeromonadaceae and positively correlated with Bacteroidaceae and Streptococcaceae.

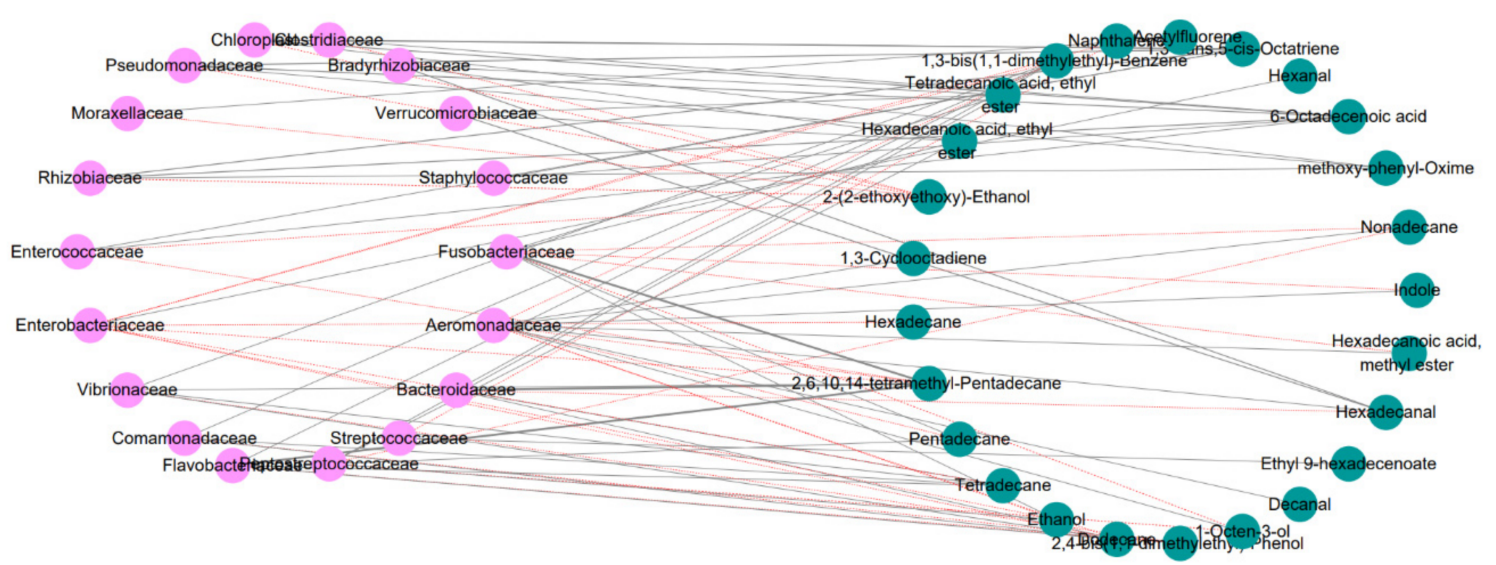

Figure 9. Correlation network analysis plot of intestinal flora and volatile flavor compounds. Negative correlation (red dotted line). Positive correlation (gray solid line).

Therefore, B. subtilis can inhibit the growth of Aeromonas spp., Fusobacterium spp., and Enterobacter spp. during the storage of fish by regulating the intestinal flora and 
reducing the production of characteristic spoilage compounds, such as indole, 1,3-bis(1,1dimethylethyl)-benzene, 2,4-bis(1,1-dimethylethyl)-phenol, and 1-octen-3-ol.

\section{Discussion}

Probiotics can antagonize spoilage bacteria by producing antibacterial substances and inhibiting adhesion. However, the prerequisite for probiotics to play a probiotic role is adhesion and colonization on the host surface [39]. In this study, high-adhesion B. subtilis C6 and B08 had stronger adhesion antagonistic effects on Pseudomonas spp. High-adhesion probiotics can effectively adhere to the gastrointestinal mucosa, exerting a space-occupying colonization effect. As a result, spoilage bacteria are hindered from contacting the intestinal mucosa, thus reducing adhesion, colonization, and reproduction. It has been found that Lactobacillus spp. antagonized Listeria monocytogenes, Salmonella typhi, and E. coli O157: H7 mainly by competition and exclusion adhesion inhibition. The Lactobacil lus spp. interfered with the interaction between pathogens and host cells, preventing their adhesion and further colonization [40]. Some studies showed Lactobacillus plantarum mainly antagonized the colonization of $E$. coli by exclusion and competition adhesion inhibition [19]. This study indicated that high-adhesion B. subtilis $\mathrm{C} 6$ had strong inhibition abilities in competition, displacement, and exclusion. The antagonistic effect of different probiotics on the adhesion of spoilage bacteria is related to many factors, such as cell surface adhesion, adhesion sites, surface proteins, and strain specificity [41].

Real-time quantitative PCR (qPCR) results showed that the in vitro adhesion model could predict the adhesion of $B$. subtilis to tilapia intestine and the inhibition of adhesion to Pseudomonas spp. The inhibition of high-adhesion B. subtilis effectively reduced the total number of bacteria and the content of TVB-N in fish intestines and flesh. B. subtilis is widely used to regulate the intestinal flora of fish. Previous studies have shown that $B$. subtilis can regulate the intestinal microbiota of grass carp and promote a healthy intestinal system [42]. In some studies, it was used in the preservation of fish filets because of its antibacterial effect or quorum-quenching mechanism. For example, researchers fed bass B. subtilis BA37, which significantly improved the survival rate and shelf life of young fish [43]. This study uses the adhesion inhibition of B. subtilis to Pseudomonas spp. to start with the intestinal tract of chilled fish, which represents a new strategy of preservation.

More interestingly, the changes in flora were measured by high-throughput sequencing, and the changes in volatile flavor substances were analyzed by GC-MS. B. subtilis not only maintained the freshness of fish (TVB-N and total number of bacteria) but also improved the flavor of fish from the perspective of regulating intestinal flora. In the feeding experiment of tilapia, when Pseudomonas spp. L. was added to the water, the main products were indole, phenol, 3-methyl-1-butanol, 1,3-bis(1,1-dimethylethyl)-benzene and 2,4-bis(1,1-dimethylethyl)-phenol, which are typical volatile components related to the putrefaction of freshwater fish [44]. However, after feeding them the B. subtilis diet, the variety and quantity of these compounds decreased.

At the same time, high-throughput sequencing and principal component analysis (PCA) identified Aeromonadaceae, Streptococcaceae, Enterobacteriaceae and Pseudomonadaceae as having the highest abundances in fish. The spoilage activity of Pseudomonas spp. is mainly due to the production of some volatile organic compounds during low-temperature storage [45]. Pseudomonas spp. is considered an important contributor to the production of aldehydes, alcohols, and esters. Its characteristic odor after infecting fish is best described as acidic. Aeromonas spp. are specific spoilage bacteria in aquatic products, and they can often be isolated from deteriorated seafood. Aeromonas spp. can use glucose to produce acid and gas, thus forming a disgusting smell of corruption [46]. Fusobacteriaceae are the main spoilage bacteria in aquatic products captured in polluted water. Their metabolites in carbohydrate fermentation pathways are mixed organic acids or alcohols [47]. The Streptococcaceae bacteria are common in the intestinal tract, most of which are not pathogenic [48]. However, the abundance of these bacteria decreased in the samples treated with $B$. subtilis. It is widely accepted that $B$. subtilis can regulate the intestinal flora 
of fish. Studies have found that the intestinal microbial structure improved after treatment, and the abundance of E. coli, Shigella spp. and Enterococcus spp. decreased significantly in the group fed with $B$. subtilis [7]. In general, B. subtilis can improve the pathogenic bacteria in this work, such as E. coli, Enterococcus spp., Aeromonas hydrophila and so on. B. subtilis can also inhibit the growth of spoilage bacteria.

\section{Conclusions}

In conclusion, we developed a new preservation method for fish products. The mucus adhesion model was used to screen for $B$. subtilis with strong inhibitory effects against Pseudomonas spp. adhesion. Subsequently, we conducted a tilapia feeding test. Through in vitro and in vivo experiments, the antagonistic effect of B. subtilis on Pseudomonas spp. increased with the enhancement of its adhesion ability. High adhesion B. subtilis C6 inhibited the colonization of Pseudomonas spp. and maintained the balance of intestinal flora, thus effectively reducing the formation of putrid odor compounds. Thus, B. subtilis is an attractive microecological preservative, and its adhesion ability is an important index for screening effective strains.

Supplementary Materials: The following are available online at https:/ /www.mdpi.com/article/10 .3390/foods10123093/s1: Figure S1: Phylogenetic tree analysis plot of 56 bacterial strains isolated from tilapia body and its living environment, Table S1: Determination of volatile flavor compounds in fish flesh after storage for zero and eight days by GC-MS, Table S2: Key flavor compounds and their odor characterization based on PLS-DA model.

Author Contributions: W.Z.: Conceptualization, Methodology, Funding acquisition, Supervision, Writing—original draft preparation, Writing—review and editing, Project administration. Q.T.: Conceptualization, Visualization, Data curation, Software, Writing_review and editing. J.Y.: Conceptualization, Writing — original draft preparation, Writing-review and editing. X.L.: Writing-review and editing. Z.L.: Writing-review and editing. L.N.: Conceptualization, Funding acquisition, Supervision, Writing - review and editing, Project administration. All authors have read and agreed to the published version of the manuscript.

Funding: This work was financially supported by the Natural Science Foundation of Fujian Province, China (No. 2020J01487) and the Science and Technology Project of Fuzhou (No. 2020-GX-13).

Acknowledgments: We thank the Minhou pilot base of Fujian Freshwater Research Institute for providing tilapia for this work.

Conflicts of Interest: The authors declare no conflict of interest.

\section{References}

1. Hoseinifar, S.H.; Sun, Y.Z.; Wang, A.; Zhou, Z. Probiotics as Means of Diseases Control in Aquaculture, a Review of Current Knowledge and Future Perspectives. Front. Microbiol. 2018, 9, 2429. [CrossRef] [PubMed]

2. Newaj-Fyzul, A.; Austin, B. Probiotics, immunostimulants, plant products and oral vaccines, and their role as feed supplements in the control of bacterial fish diseases. J. Fish Dis. 2015, 38, 937-955. [CrossRef] [PubMed]

3. Lorentzen, G.; Ageeva, T.N.; Heide, M.; Esaiassen, M. Temperature fluctuations in processing and distribution: Effect on the shelf life of fresh cod fillets (Gadus morhua L.). Food Control 2020, 112, 107102. [CrossRef]

4. Meidong, R.; Khotchanalekha, K.; Doolgindachbaporn, S.; Nagasawa, T.; Nakao, M.; Sakai, K.; Tongpim, S. Evaluation of probiotic Bacillus aerius B81e isolated from healthy hybrid catfish on growth, disease resistance and innate immunity of Pla-mong Pangasius bocourti. Fish Shellfish Immunol. 2018, 73, 1-10. [CrossRef]

5. Ding, H.; Ruan, D.; Jiang, Y.; Xu, G.; Huang, J. Analysis and comparison of cooked high-value sea fish surimi volatile flavor. Food Ferment. Ind. 2015, 41, 163-169.

6. Molham, F.; Khairalla, A.S.; Azmy, A.F.; El-Gebaly, E.; El-Gendy, A.O.; AbdelGhani, S. Anti-Proliferative and Anti-Biofilm Potentials of Bacteriocins Produced by Non-PathogenicEnterococcussp. Probiotics Antimicrob. Proteins 2021, 13, 571-585. [CrossRef]

7. Liu, Y.Q.; Yin, F.; Huang, L.S.; Teng, H.F.; Shen, T.Y.; Qin, H.L. Long-term and continuous administration of Bacillus subtilis during remission effectively maintains the remission of inflammatory bowel disease by protecting intestinal integrity, regulating epithelial proliferation, and reshaping microbial structure and function. Food Funct. 2021, 12, 2201-2210. [PubMed]

8. Gram, L.; Dalgaard, P. Fish spoilage bacteria-problems and solutions. Curr. Opin. Biotechnol. 2002, 13, 262-266. [CrossRef] 
9. Aliakbarpour, H.R.; Chamani, M.; Rahimi, G.; Sadeghi, A.A.; Qujeq, D. The Bacillus subtilis and Lactic Acid Bacteria Probiotics Influences Intestinal Mucin Gene Expression, Histomorphology and Growth Performance in Broilers. Asian-Aust. J. Anim. Sci. 2012, 25, 1285-1293. [CrossRef]

10. Wang, A.; Ran, C.; Wang, Y.; Zhang, Z.; Ding, Q.; Yang, Y.; Olsen, R.E.; Ringo, E.; Bindelle, J.; Zhou, Z. Use of probiotics in aquaculture of China-a review of the past decade. Fish Shellfish Immunol. 2019, 86, 734-755. [CrossRef]

11. Zhang, C.; Zhu, F.; Jatt, A.N.; Liu, H.; Niu, L.; Zhang, L.; Liu, Y. Characterization of co-culture of Aeromonas and Pseudomonas bacterial biofilm and spoilage potential on refrigerated grass carp (Ctenopharyngodon idellus). Lett. Appl. Microbiol 2020, 71, 337-344.

12. Dabadé, D.S.; den Besten, H.M.; Azokpota, P.; Nout, M.R.; Hounhouigan, D.J.; Zwietering, M.H. Spoilage evaluation, shelf-life prediction, and potential spoilage organisms of tropical brackish water shrimp (Penaeus notialis) at different storage temperatures. Food Microbiol. 2015, 48, 8-16. [CrossRef]

13. Kesel, S.; Mader, A.; Seeberger, P.H.; Lieleg, O.; Opitz, M. Carbohydrate Coating Reduces Adhesion of Biofilm-Forming Bacillus subtilis to Gold Surfaces. Appl. Environ. Microbiol. 2014, 80, 5911. [CrossRef] [PubMed]

14. Hori, K.; Matsumoto, S. Bacterial adhesion: From mechanism to control. Biochem. Eng. J. 2010, 48, 424-434. [CrossRef]

15. Slizewska, K.; Chlebicz-Wojcik, A.; Nowak, A. Probiotic Properties of New Lactobacillus Strains Intended to Be Used as Feed Additives for Monogastric Animals. Probiotics Antimicrob. Proteins 2021, 13, 146-162. [CrossRef] [PubMed]

16. Ye, X.; Li, P.; Yu, Q.; Yang, Q. Bacillus subtilis inhibition of enterotoxic Escherichia coli-induced activation of MAPK signaling pathways in Caco-2 cells. Ann. Microbiol. 2013, 63, 577-581. [CrossRef]

17. Piewngam, P.; Zheng, Y.; Nguyen, T.H.; Dickey, S.W.; Joo, H.S.; Villaruz, A.E.; Glose, K.A.; Fisher, E.L.; Hunt, R.L.; Li, B.; et al. Pathogen elimination by probiotic Bacillus via signalling interference. Nature 2018, 562, 532-537. [CrossRef]

18. Giri, S.S.; Ryu, E.C.; Sukumaran, V.; Park, S.C. Antioxidant, antibacterial, and anti-adhesive activities of biosurfactants isolated from Bacillus strains. Microb. Pathog. 2019, 132, 66-72. [CrossRef]

19. Lau, L.Y.J.; Chye, F.Y. Antagonistic effects of Lactobacillus plantarum 0612 on the adhesion of selected foodborne enteropathogens in various colonic environments. Food Control 2018, 91, 237-247.

20. Zhang, W.; Lv, X.; Liu, Z.; Ni, L. The spoilage and adhesion inhibitory effects of Bacillus subtilis against Shewanella and Pseudomonas in large yellow croaker (Pseudosciaena crocea). Food Sci. Technol. 2021, 10, 02721. [CrossRef]

21. Larsen, M.H.; Larsen, J.L.; Olsen, J.E. Chemotaxis of Vibrio anguillarum to fish mucus: Role of the origin of the fish mucus, the fish species and the serogroup of the pathogen. FEMS Microbiol. Ecol. 2001, 38, 77-80. [CrossRef]

22. Forestier, C.; Champs, C.D.; Vatoux, C.; Joly, B. Probiotic activities of Lactobacillus casei rhamnosus: In vitro adherence to intestinal cells and antimicrobial properties. Res. Microbiol. 2001, 152, 167-173. [CrossRef]

23. GB 5009.228-2016. National Food Safety Standard-Determination of Volatile Salt-Based Nitrogen in Foods; Standards Press of China: Beijing, China, 2016; Volume 1, pp. 3-5.

24. Xue, W.; Chun, L.; Jing, W.; Qiao, Z.; Zhi, D. Identification and analysis of the flavor components in the fermentation of Siniperca Scherzeri. Chin. J. Food Sci. 2015, 15, 222-229.

25. Guojun, G.; Qingpi, Y.; Wenzheng, Z.; Rensun, Z.; Changsheng, C.; Qiang, C. Influence of antagonistic bacteria on adhesion of pathogenic vibrio alginoyticus to skin MUCUS of pseudoscaena crocea. Ocean. Lakes 2009, 40, 738-744.

26. Weng, Z.; Dan, B.; Cheng, R.; Xiang, S. Adhesion and biofilm characteristics of spoilage bacteria from large yellow croaker pseudosciaena crocea. Food Sci. 2019, 40, 14.

27. Wang, X.Y.; Xie, J. Growth Kinetics and Spoilage Potential of Co-culturing Acinetobacter johnsonii and Pseudomonas fluorescens from Bigeye Tuna (Thunnus obesus) During Refrigerated Storage. Curr. Microbiol. 2020, 77, 1637-1646. [CrossRef]

28. Guo, H.X.; Sun, Z.Y.; Hao, Y.; Zhang, L.Y.; Ren, Y.T.; Zhang, Y.; Chen, Z.J. Correlation between bacterial communities and organic acids in the fermentation stage of traditional Chinese sour porridge. Int. J. Food Prop. 2020, 23, 1430-1440. [CrossRef]

29. Parlapani, F.F.; Michailidou, S.; Anagnostopoulos, D.A.; Koromilas, S.; Kios, K.; Pasentsis, K.; Psomopoulos, F.; Argiriou, A.; Haroutounian, S.A.; Boziaris, I.S. Bacterial communities and potential spoilage markers of whole blue crab (Callinectes sapidus) stored under commercial simulated conditions. Food Microbiol. 2019, 82, 325-333. [CrossRef]

30. Wu, S.Z.; Hou, W.J.; Suo, X.K.; Guo, X.P.; Li, H. Bacillus subtilis extracellular polymeric substances conditioning layers inhibit Escherichia coli adhesion to silicon surfaces: A potential candidate for interfacial antifouling additives. Biointerphases 2021, 16, 011003. [CrossRef] [PubMed]

31. Chen, Y.P.; Cai, D.D.; Li, W.Q.; Blank, R.; Liu, Y. Application of gas chromatography-ion mobility spectrometry (GC-IMS) and ultrafast gas chromatography electronic-nose (uf-GC E-nose) to distinguish four Chinese freshwater fishes at both raw and cooked status. J. Food Biochem. 2021, 1, 13840. [CrossRef] [PubMed]

32. Wang, Y.; Li, C.; Li, L.; Yang, X.; Chen, S.; Wu, Y.; Zhao, Y.; Wei, Y. Analysis of volatile flavor components and fatty acids in fish sauces during fermentation by GC-MS. J. Fish. China 2018, 42, 984-995.

33. Liu, Y.; Huang, Y.Z.; Wang, Z.M.; Cai, S.H.; Zhu, B.W.; Dong, X.P. Recent advances in fishy odour in aquatic fish products, from formation to control. Int. J. Food Sci. Technol. 2021, 10, 15269. [CrossRef]

34. Chen, J.H.; Tao, L.N.; Zhang, T.; Zhang, J.J.; Wu, T.T.; Luan, D.L.; Ni, L.; Wang, X.C.; Zhong, J. Effect of four types of thermal processing methods on the aroma profiles of acidity regulator-treated tilapia muscles using E-nose, HS-SPME-GC-MS, and HS-GC-IMS. LWT-Food Sci. Technol. 2021, 147, 111585. [CrossRef] 
35. Wu, Y.; You, G.; Li, L.; Yang, X.; Deng, J.; Chen, S. Comparison of flavor components between low-salt lactic acid fermented fish and traditional salted fish. J. Fish. China 2014, 38, 601-612.

36. Kang, C.; Shi, W.; Fang, L.; Wang, X. Effects of Different Freezing Methods on the Volatile Components of Grass Carp Meat. Food Sci. 2018, 39, 229-235.

37. Curioni, P.M.G.; Bosset, J.O. Key odorants in various cheese types as determined by gas chromatography-olfactometry. Int. Dairy J. 2002, 12, 959-984. [CrossRef]

38. Li, Y.; Huang, J.; Yuan, C.; Ding, T.; Chen, S.; Hu, Y. Developing a new spoilage potential algorithm and identifying spoilage volatiles in small yellow croaker (Larimichthys polyactis) under vacuum packaging condition. Lebensm. Wiss. Technol 2019, 106, 209-217. [CrossRef]

39. Singh, T.P.; Gurpreet, K.; Suman, K.; Malik, R.K. Antagonistic Activity of Lactobacillus reuteri Strains on the Adhesion Characteristics of Selected Pathogens. Front. Microbiol. 2017, 8, 486. [CrossRef]

40. Gómez, N.C.; Ramiro, J.M.; Quecan, B.X.; de Melo Franco, B.D. Use of Potential Probiotic Lactic Acid Bacteria (LAB) Biofilms for the Control of Listeria monocytogenes, Salmonella Typhimurium, and Escherichia coli O157:H7 Biofilms Formation. Front. Microbiol. 2016, 7, 863. [CrossRef]

41. Dandan, Z.; Mengting, W.; Yuxing, G. Purification of Lactobacillus acidophilus surface-layer protein and its immunomodulatory effects on RAW264.7 cells. J. Sci. Food Agric. 2017, 97, 12.

42. Shi, F.; Zi, Y.J.; Lu, Z.J.; Li, F.L.; Yang, M.X.; Zhan, F.B.; Li, Y.N.; Li, J.; Zhao, L.J.; Lin, L.; et al. Bacillus subtilis H2 modulates immune response, fat metabolism and bacterial flora in the gut of grass carp (Ctenopharyngodon idellus). Fish Shellfish Immunol. 2020, 106, 8-20. [CrossRef] [PubMed]

43. Nair, A.V.; Antony, M.L.; Praveen, N.K.; Sayooj, P.; Swaminathan, T.R.; Vijayan, K.K. Evaluation of in vitro and in vivo potential of Bacillus subtilis MBTDCMFRI Ba37 as a candidate probiont in fish health management. Microb. Pathog. 2021, 152, 104610. [CrossRef]

44. Zhu, J.; Zhao, A.; Feng, L.; Gao, H. Quorum sensing signals affect spoilage of refrigerated large yellow croaker (Pseudosciaena crocea) by Shewanella baltica. Int. J. Food Microbiol. 2016, 217, 146-155. [CrossRef] [PubMed]

45. Ercolini, D.; Casaburi, A.; Nasi, A.; Ferrocino, I.; di Monaco, R.; Ferranti, P.; Mauriello, G.; Villani, F. Different molecular types of Pseudomonas fragi have the same overall behaviour as meat spoilers. Int. J. Food Microbiol. 2010, 142, 120-131. [CrossRef]

46. Dong, J.; Zhang, L.; Liu, Y.; Zhou, S.; Yang, Y.; Xu, N.; Yang, Q.; Ai, X. Resveratrol influences the pathogenesis of Aeromonas hydrophila by inhibiting production of aerolysin and biofilm. Food Control 2021, 126, 108083. [CrossRef]

47. Shen, Y.Y.; Wu, Y.Y.; Wang, Y.Q.; Li, L.H.; Li, C.S.; Zhao, Y.Q.; Yang, S.L. Contribution of autochthonous microbiota succession to flavor formation during Chinese fermented mandarin fish (Siniperca chuatsi). Food Chem. 2021, 348, 129107. [CrossRef]

48. Zhang, J.; Zhang, H.; Wang, L.; Zhang, K.; Qiu, Z.; Zhang, K.; Yue, C.; Zhang, Y.; Li, J.; Zhao, X. The safety and potential probiotic properties analysis of Streptococcus alactolyticus strain FGM isolated from the chicken cecum. Ann. Microbiol. 2021, 71, 1-14. 